\title{
3D GEO-INFORMATION REQUIREMENTS FOR DISASTER AND EMERGENCY MANAGEMENT
}

\author{
E. Demir Ozbek ${ }^{\text {a }, ~ S . ~ Z l a t a n o v a ~}{ }^{\text {b }, ~ S . ~ A t e s ~ A y d a r ~ a, ~ *, ~ T . ~ Y o m r a l i o g l u ~}{ }^{\text {a }}$ \\ ${ }^{a}$ Department. of Geomatics Engineering, Civil Engineering Faculty, ITU, Maslak, Istanbul, Turkey, 34469 - \\ (demirelif, atesser, tahsin)@itu.edu.tr \\ b 3D Geoinformation Group, Department of Urbanism, Faculty of Architecture and the Built Environment, TU Delft, Delft, 2628BL, \\ The Netherlands- S.Zlatanova@tudelft.nl
}

KEY WORDS: 3D Geo-information, Data Requirements, Disaster and Emergency Management

\begin{abstract}
:
A conceptual approach is proposed to define 3D geo-information requirement for different types of disasters. This approach includes components such as Disaster Type-Sector-Actor-Process-Activity-Task-Data. According to disaster types processes, activities, tasks, sectors, and responsible and operational actors are derived. Based on the tasks, the needed level of detail for 3D geo-information model is determined. The levels of detail are compliant with the 3D international standard CityGML. After a brief introduction on the disaster phases and geo-information requirement for actors to perform the tasks, the paper discusses the current situation of disaster and emergency management in Turkey and elaborates on components of conceptual approach. This paper discusses the 3D geo-information requirements for the tasks to be used in the framework of 3D geo-information model for Disaster and Emergency Management System in Turkey. The framework is demonstrated for an industrial fire case in Turkey.
\end{abstract}

\section{INTRODUCTION}

To find requirements for a useful Disaster and Emergency Management System (DEMS), it is necessary to know how to describe and characterize Disaster and Emergency Management (DEM) itself. DEM is divided into four phases namely: Mitigation, Preparation, Response and Recovery. These phases are currently widely accepted by all kind of agencies all over the world (Zlatanova and Holweg, 2004). The mitigation phase deals with risk reduction, i.e. prevention or attenuating that a disaster can actually happen (Franke and Charoy, 2010). Preparation phase deals with planning and training for disaster response and enhancing the capacity of the response units and resources (FEMA, 2006). The response phase is concerned with counteracting a disaster in the immediate aftermath of its occurrence and, thus, with the management and execution of disaster response processes (Sackmann et al., 2013). In the response phase different organizations with low and high dependency on each other fight the disaster and its consequences. The recovery phase is about debriefing from the response and reconstruction of the social processes of the affected communities (Franke and Charoy, 2010).

Factors causing disasters can be reduced or mitigated with an effective DEM approach, which should be considered as an integrated system including before, during and after disaster occurs. Integrated DEM includes all valuable resources of all disaster types and emergencies related to the phases of DEM. (Aydinoglu et al., 2011; Bhugra, 2005; Benson and Twigg, 2007; Vakis, 2006). DEM procedures may significantly differ per country because they reflect the vulnerability and preparedness of the country for disasters. The organizational structure for DEM may also differ. However, all governments have legislations that prescribe work-flows and procedure for the processes of DEM. Using these documents and analysing the work of the actors, it is possible to specify what kind of geo-information might be of primarily interest when performing a certain tasks (Zlatanova, 2010).

Any disaster incident is managed through processes and activities which are performed by various actors (Demir Ozbek et al, 2015). Each activity has a well-defined objective, which realization requires certain information and often produces information (Dilo and Zlatanova, 2008). DEM compared to other applications of geo-information, is that the requirement for integration of data representing above and below the surface, indoor and outdoor, which implies 3D modelling and management of information (Zlatanova et al., 2004, 2012). 3D models have been developed throughout the years within various domains and for different purposes (Zlatanova et al, 2012). Nevertheless, there is a lack of 3D geo-information model for integrated DEMS.

There are different types of objects in DEMS geo-information model (DEMS-GDM). These objects have to be visualized or analysed in both 2D and 3D. However, all objects in DEMSGDM are not need to have 3D information. In DEM, 3D modelling is very much dependent on the type of disasters to be represented and the type of users to be involved in the DEM process (Kemec et al, 2009). Therefore, there are different LODs are needed for different disaster types and for different processes. LODs are required to reflect independent geo-information requirements for different tasks. Each task may need specific LODs for 3D data objects.

\footnotetext{
* Corresponding author
} 
In this context, as a preliminary work to use 3D data effectively in DEM processes, actor, activities, tasks and 3D geoinformation requirements were examined in the study. Disaster types from Turkish National Disaster Response Plan (TAMP) are analysed into four phases: mitigation, preparation, response and recovery. Processes, activities and tasks of disaster types and actors that are responsible for these tasks are derived from legislation and literature study. Based on the disaster type, the needed level of detail for 3D geo-information model is derived. To determine 3D geo-information requirement, a two-step approach is followed. In the first step, 3D geo-information requirements are determined according to activities of different disaster types. It seems that additional DEM related objects beside the standard objects of a $3 \mathrm{D}$ model are also of need. In the second step, LODs requirement of $3 \mathrm{D}$ objects for each task is determined according to needs of actors to perform the tasks.

In this study, the levels of detail (LOD) used to specify 3D geoinformation requirements are compliant with the 3D international standard CityGML which has strong characteristics of semantics and geometry. The semantic aspect of information is critical for DEM because of semantic heterogeneity at different levels: data, organization, process, etc. (Pundt, 2008, Xu and Zlatanova, 2007; Zlatanova, 2008). CityGML supports 5 different LOD. The coarsest level LOD0 is essentially a $2.5 \mathrm{D}$ Digital Terrain Model (DTM). LOD1 is the well-known blocks model comprising prismatic buildings with flat roof structures. In contrast, a building in LOD2 has differentiated roof structures and thematically differentiated boundary surfaces. LOD3 denotes architectural models with detailed wall and roof structures including doors and windows. LOD4 completes a LOD3 model by adding interior structures for 3D objects (OGC, 2007).

In this paper, Section 2 explains current organizational structure of DEM in Turkey. Section 3 explains the approach in order to develop DEMS 3D geo-information model as a sector model of Turkish National GIS (TUCBS) at provincial level. This approach includes disaster type, sector, actor, process, activity, and task components to interact with 3D geo-information and is defined with UML diagrams. Section 4 gives an overview about 3D geoinformation requirements with required level of detail information for industrial fire disaster tasks. Section 5 closes the paper with conclusions and expectations.

\section{CURRENT SITUATION OF DISASTER AND EMERGENCY MANAGEMENT IN TURKEY}

Before analysing 3D geo-information requirements for DEM activities, the existing DEM organization of Turkey is examined. In Turkey, DEM organizational structure is defined with national and local level. The actors in national and local level are coordination and/or operation teams.

The duties of coordination units at national level are to specify and to approve the politic directive guidelines, reports, programs and plans, to supervise the emergency centres, to ensure the coordination between agencies, institutes and NGOs, to assess the information coming from disaster region, and to specify the actions to be taken. The duties of coordination unit at local level are to prepare the incident type plans, to confirm the provincial disaster response plan and provincial service group operational plans, and to integrate the service group plan with the provincial disaster response plan.

Operation units at national level are Prime Ministry Disaster and Emergency Management Centre (PMDEMC) and Ministry
Disaster and Emergency Management Centre (MDEMC). Main operation unit at local level is Provincial Disaster and Emergency Management Centre (PDEMC). These three units form the DEM triangle in Turkey.

The actors and their tasks within a DEM activity depend on the goal of the process and the complexity of the incident. The complexity of incident is measured by the effects and the area it covers (Zlatanova, 2010). In Turkey, disasters are divided into 4 levels according to their response capacity requirements and degree of influence. PMDEMC ensures the response and coordination at national level in case of 3th and 4th level disasters. PDEMC ensures the response and coordination at local level. MDEMCs are formed within the ministries which are the main solution partner of National Service Group (NSG). NSGs are constituted from main solution partners and supporting solution partners consisted of concerned ministries, institutions and NGOs. Disaster response management at local level is designed as a single model of national level on the purpose of ensuring the standardization throughout the country. NSGs are represented as Provincial Service Groups (PSG) in PDEMC at local level with the same structure at national level.

Disaster response organization has four main services: operation service, logistic and maintenance service, information and planning service, and financial and administrative affairs service. Operation Service, which implement the response plan as a main unit, is divided into two sub-services: Emergency Services and Pre-Recovery Services. Totally 28 service groups are defined as shown in Figure 1 (TAMP, 2013).

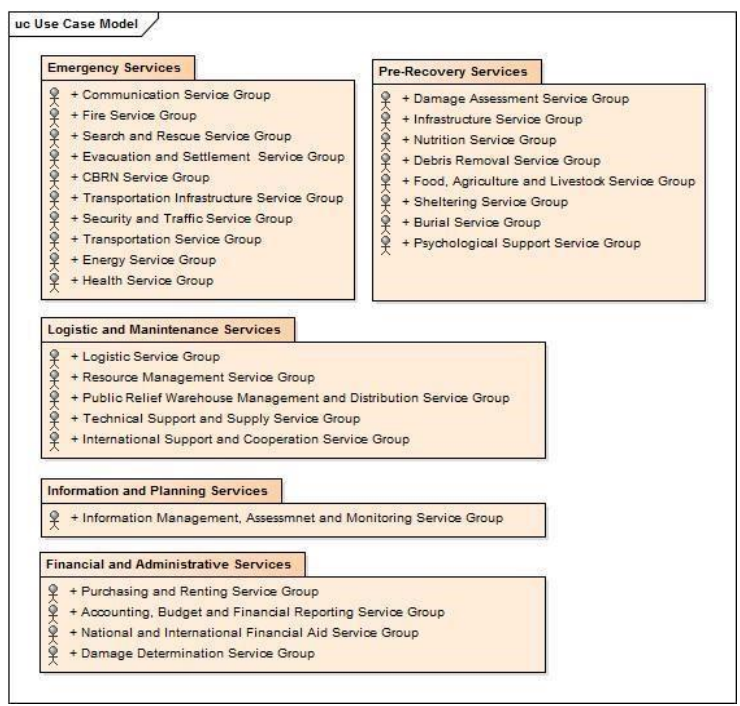

Figure 1: National service groups in Turkey

Plan types for DEM in Turkey are divided into three groups: strategic plans, tactical plans and operational plans. Turkey Disaster Management Strategy Paper is under development in strategic level. In tactical level, Turkey Disaster Response Plan is in force and Turkey Disaster Risk Mitigation Plan and Turkey Disaster Recovery Plan are still under development. National Level Service Group Plans, Provincial Disaster Response Plans and Local Level Service Group Plans are under development in operation level. According to TAMP, incident type plans and service group plans at national and local level should be prepared. These plans, which are directly linked to this study in respect to specify actors and activities of disaster types, are not yet prepared. For this reason, actors and activities are determined with literature search and analysing various legislation. 


\section{GENERAL CONCEPTUAL APPROACH FOR DISASTER AND EMERGENCY MANAGEMENT SYSTEM}

The conceptualization of DEMS-GDM is based on providing the most effective data flow in DEM. Thus, the general conceptual approach of DEMS is defined with Disaster Type - Sector Actor - Process - Activity - Task - Data components (Figure 2).

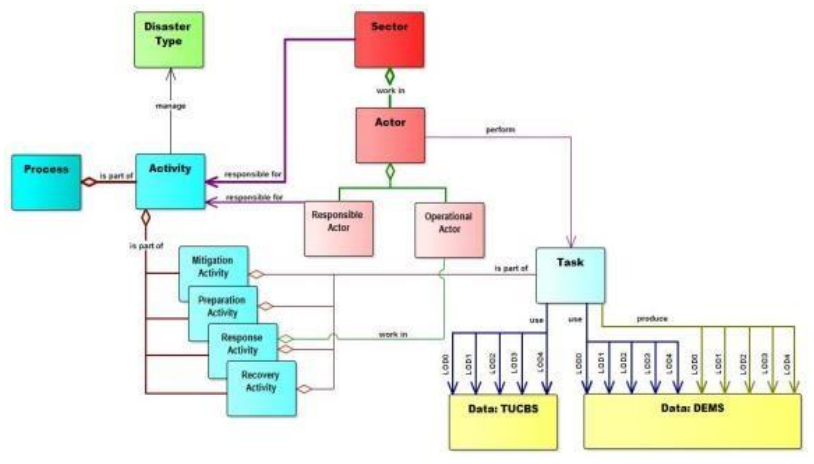

Figure 2: General conceptual approach for DEMS

\subsection{Disaster Type}

According to TAMP, 12 disaster types are defined for Turkey. These are "earthquake", "flood", "forest fire", "industrial fire", "biological and epidemics disaster", "chemical disasters", "collective population movement", "cyber-attack", "dam explosion", "drought", "radiologic and nuclear accidents" and "transportation accidents". In this study, industrial fire case is selected to determine $3 \mathrm{D}$ geo-information requirements.

\subsection{Sector}

In Turkey, sectors involved in DEM are identified as service groups. There are 28 service groups which are explained in Section 2. 16 Service Groups responsible for industrial fire disaster are "Communication", "Security and Traffic", "Transportation Infrastructure", "Search and Rescue", "Transportation", "Health", "Evacuation and Settlement", "Infrastructure", "Energy", "Sheltering", "Damage Assessment", "Fire", "Debris Removal", "Technical Support and Supply", "Damage Determination", and "CBRN".

\subsection{Actor}

Actor is an organization, institution or a person which is involved in DEM. Every sector has more than one actor with different roles. Actors that have responsibilities on DEM were determined by examining the legislation. The actors which take part in DEM activities are levelled as governmental, national, regional, provincial and local according to their hierarchical relation.

According to their roles, two types of actor are identified; responsible actors and operational actors.

Responsible actor is liable for activities at preparation, mitigation, response and recovery DEM.

Operational actor served in disaster area is responsible for sub activities of the response phase.

"112 Emergency Call Centre" within "Communication Sector", "Fire Brigade" within "Fire Sector", "Police" within "Security and Traffic Sector", and "Ambulance" within "Health Sector" can be given as examples for the operational actors involved in industrial fire management. "Turkish Radio and Television Association" within "Communication Sector", "Forestry Operation Directorate" within "Fire Sector", and "Gendarmerie" within "Security and Traffic Sector", and "Health Board" within "Health Sector" can be given as examples for the responsible actors.

\subsection{Process}

Processes are identified as general activities for the mitigation, preparation, response and recovery phases of selected disasters. Processes are common for all disasters and all disasters will be integrated with using these processes. There are 42 processes within 13 main title for four phases of DEM (Figure 3).

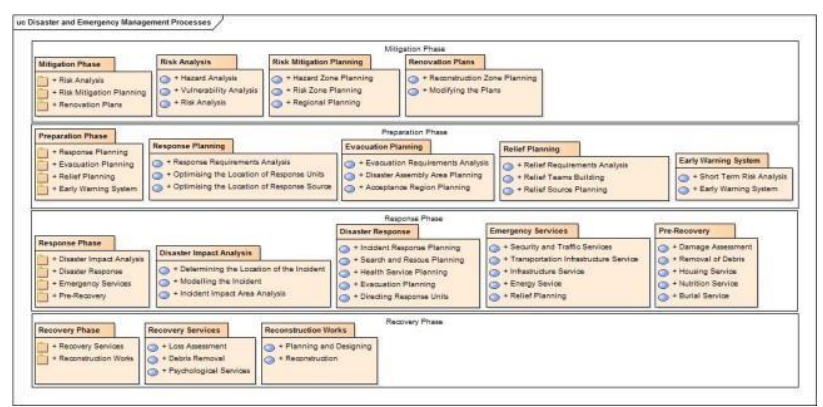

Figure 3: Disaster and emergency management processes

\subsection{Activity}

All phases of DEM are managed through activities. Each sector is responsible for some activities. Each process has several activities according to disaster type. Totally 234 industrial fire activity types within 42 disaster processes are determined. The activities of "Hazard Analysis", "Vulnerability Analysis" and "Risk Analysis" processes for industrial fire disaster are shown in Figure 4.

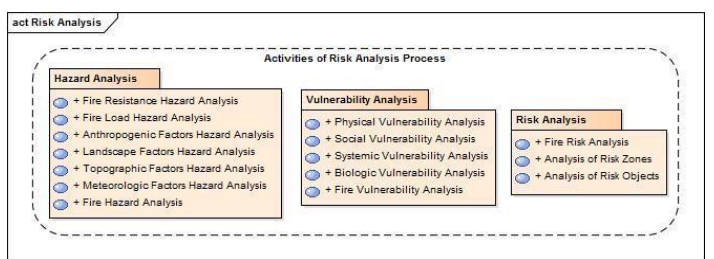

Figure 4: Activities of risk analysis process

\subsection{Task}

Every activity are formed by tasks. In other words, emergency activities comprise tasks and an actor performs task. A task requires and produces information during emergency event. In Figure 5, the tasks of "Fire Resistance Hazard Analysis Activity" are shown as an example for industrial fire disaster.

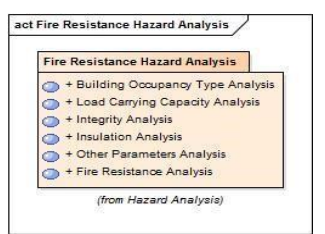

Figure 5: Tasks of fire resistance hazard analysis activity 


\subsection{Data}

Actor needs some existing data from TUCBS geodatabase and also some existing and/or dynamic data from DEMS geodatabase to perform the tasks. And, this task produces some dynamic data on DEMS geodatabase during disaster. TUCBS is also 2D National Data Exchange Model but effective DEM needs 3D geoinformation to manage processes. In this study, 3D geoinformation requirements for performing the tasks are determined according to OGC CityGML Standard 3D principles. CityGML is an international standard for the representation and exchange of semantic 3D city and landscape models recently adopted by the Open Geospatial Consortium (OGC). The data model behind CityGML is based on the ISO 19100 standards family and is implemented as an application schema for OGC's GML (Kolbe, 2009).

In this study, LOD requirements of objects used and produced in tasks are determined. CityGML provides the concept of a LOD, which is best developed for buildings. However, the approach of CityGML is appropriate for the introduction of LOD levels for various other objects. In CityGML, LODs range from LOD0 to LoD4. LOD0 is the 2.5D level, over which an aerial image or a map may be draped, for a simple box model defines buildings in LOD1, while buildings in LOD4 are defined even with interior details of them. Naturally the resolution increases from LOD0 to LOD4. The concept of LOD is quite generic and suitable for small to large area applications. The concepts of LOD of CityGML are adopted as a starting point in the study (Kemec et al, 2009; 2012; Kemec, 2011; Kolbe et al, 2005).

\section{3D GEO-INFORMATION REQUIREMENTS FOR INDUSTRIAL FIRE DISASTER}

This section focuses on determining 3D geo-information requirements with the approach defined in Section 3 for formal modelling of DEM activities in Turkey. According to this approach, 3D geo-information requirements are analysed with following a two-step approach within activity-task workflow tables.

In the first phase of the analysis, tasks which describe the workflow of the activity are defined for each activity. These tasks are performed by different actors that are interested in different sets of risk elements. That is to say, this modelling of tasks revealed that the data can be further specialized with respect to the actors. TUCBS is used as base to determine the geoinformation requirements. TUCBS data set including the general feature types: Address, Building, Cadastral Parcels, Administrative Unit, Transportation, Hydrography, Land Cover, Orthoimagery, Topography and Geodetic Infrastructure. TUCBS data set including the thematic feature types: Protected

Sites, Plan Zones, Social-Culture, Infrastructure, Natural

Resources, Bio-Diversity, Weather-Climate, and GeologyEnvironment. Feature types and their attributes of TUCBS does not always meet the geo-information requirements of the tasks. Therefore, apart from TUCBS, Inspire data sets are used to determine the geo-information requirements of DEM tasks. Furthermore, the scale of the maps differs per task/actor.

In the second phase of the analysis, LODs requirement of 3D objects for each task is determined according to needs of actors to perform the tasks. In this phase, the appropriate LOD of objects for each task are analysed and defined by a decision rule. LODs represent the indoor and outdoor resolution which defines the abstraction level of each modelling object (Kemec et al. 2012).
3D geo-information requirements are determined with using CityGML LOD principles.

A conceptualization is done between the tasks of the actors and the data for the purpose of providing the most appropriate geoinformation to each actor, who is involved in DEM tasks. In this study, an object-oriented modelling is applied and more specifically the Unified Modelling Language (UML). UML is used to represent application structures, behaviours, architecture, business process and data structures. UML is quite appropriate for modelling tasks and actors, since it gives a good overview of the classes (actors and tasks) and their relationships (Zlatanova, 2010).

\subsection{Geo-information Requirements Analysis Methodology}

In this part, the methodology is explained with the instance of "fire resistance hazard analysis" activity. For the mitigation phase of industrial fire management, first sub-process is "hazard analysis" which is a part of "risk analysis" process. This process consists of 7 activities: "fire resistance hazard analysis", "fire load hazard analysis", "anthropogenic factors hazard analysis", "landscape factors hazard analysis", "topographic factors hazard analysis", "meteorological factors hazard analysis", and "fire hazard analysis". "Fire resistance hazard analysis" activity consists of 6 tasks which form the workflow of the activity: "building occupancy type analysis", "load carrying capacity analysis", "integrity analysis", "insulation analysis", "other parameters analysis", and "fire resistance analysis". Responsible actor of "fire resistance hazard analysis" activity is Provincial Disaster and Emergency Management Directorate which determines a framework for the activity and evaluates the results. Fire Brigade is the operating actor for the activity. Figure 6 shows the process-activity-task-actor relation for "fire resistance hazard analysis" activity with UML diagram which is used to carry out the notations of the activities.

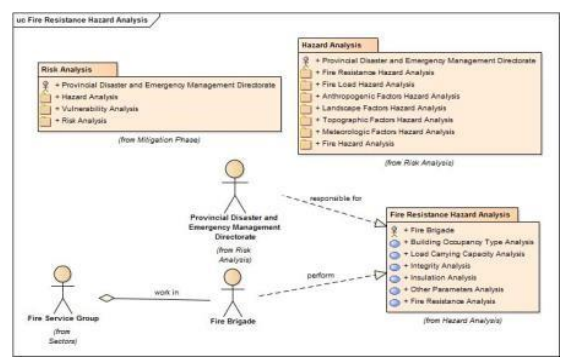

Figure 6: "Fire resistance hazard analysis" activity diagram

To perform the activities, Standard Operating Procedures (SOP), which as applied to DEM is a set of tasks designed to cover the features of operations which provide a definite sequence of carrying out tasks without loss of effectiveness, are required with use-case description. Furthermore, in order to determine the 3D geo-information requirements for the industrial fire disaster, a structured set of use cases for activities is required. Use case description with the tasks of activities defines the methodology of the industrial fire processes. For each activity, "Activity Workflow / Data Requirement Analysis" table is prepared to analyse 3D geo-information requirement.

3D geo-information requirements for "fuel resistance hazard analysis" activity is shown with the use-case description included activity workflow that is referred to as SOP (Table 1). The first row of the table includes the information about activity name and number. Activity number IF.M.1.1.1 means that "fire resistance hazard analysis" activity is the first activity of "hazard analysis" 
process which is the first sub-process of "risk analysis" process of mitigation (M) phase of industrial fire (IF) disaster. Fire brigade is seen in the table as an operational actor of the activity. In mitigation phase in contrast to the response phase, the tasks of an activity are performed by same operational actor.

The tasks which constitute this activity use data form TUCBS geo database and produce new data to TUCBS and DEMSGDM. The following activities may use this new geo data from database. Geo-information produced in mitigation phase mostly use for preparation phase and geo-information produced in preparation phase mostly use for response phase of DEM. Managing the activities of industrial fire disaster are mostly related to building feature type because of the risk location. Thus, the tasks of this sample activity use <<Building > general feature type from TUCBS and $<<$ ProductionFacility $>>$ from INSPIRE and produce $<<$ FireRiskBuilding >> feature type to DEMS-GDM.

The DEM process runs from abstract to details and therefore information should provide the actors with appropriate resolution to make it intelligible. The types of objects, their representation and the resolution, or LOD, play the most critical roles in $3 \mathrm{D}$ DEM modelling. In this context, the concepts of LOD of CityGML are used as base of a starting point for hazard type- geoinformation requirement relation. According to needs of operational actor of the task, required LOD of the object used and produced during the task is determined with literature study. In Table 1, the scale (LOD) and attributes of the required objects are shown for each task.

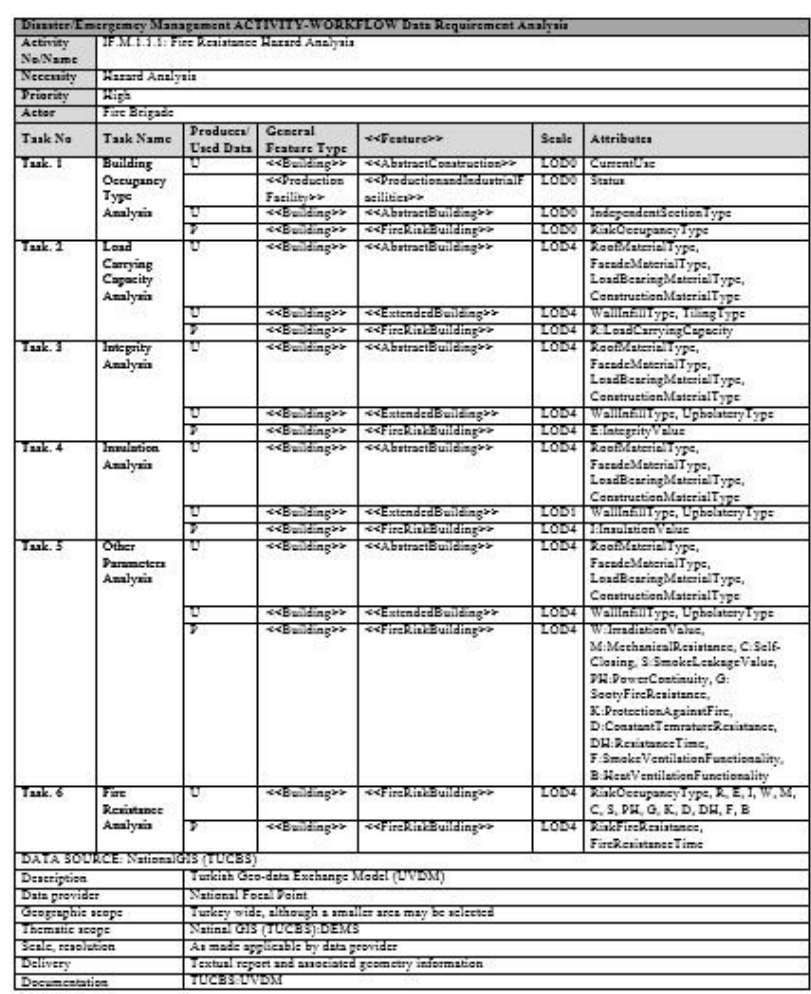

Table 1. Geo-information requirement analysis for the tasks of fire resistance hazard analysis activity

"Activity - Workflow / Geo-information Requirement Analysis" tables for all activities of industrial fire processes are filled. For all industrial fire activities as explained above, 3D geoinformation requirements analysis are performed. With respect to task type, a specific LOD is defined, which determines the leve of processing. After that, UML diagrams that have geo- information requirements are created for each task. The appropriate LOD found from the task assessment is used in 3D geo-information requirements diagram. Figure 7 shows the UML diagram that have feature types with attributes and cod lists used and produced in "building occupancy type" task. This diagram is created with using information analysed in Table 1.

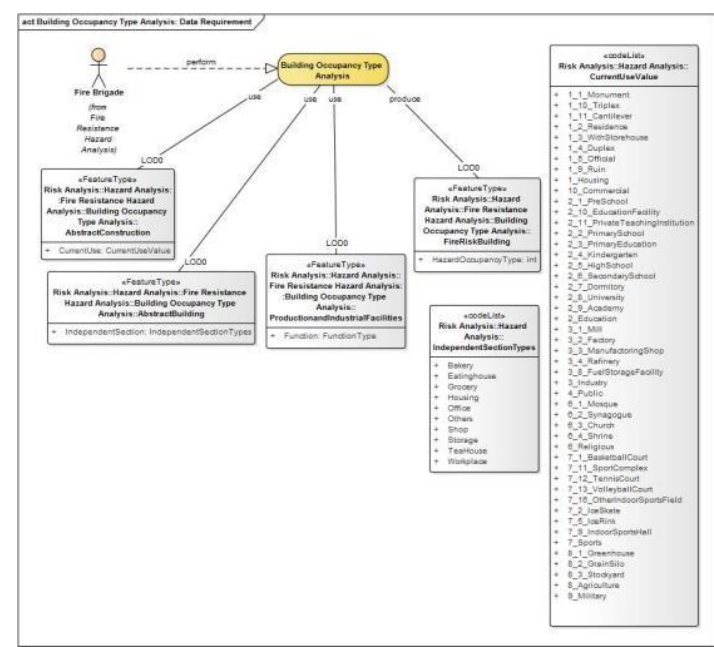

Figure 7: Geo-information requirements diagram of "building occupancy type analysis" task

The combination of task geo-information requirements constitute the activity geo-information requirements. Different LOD requirements might be determined for same object in different tasks of the activity. Figure 8 shows the geo-information requirement for "fire resistance hazard analysis" activity which has "building occupancy type analysis" task explained in Figure 7. Figure 8 shows the tasks of the activity, geo-information used for performing the tasks, LOD requirements of the geoinformation, attributes of required geo-information, required code lists, and produced <<FireRiskBuilding〉> class with required LOD information.

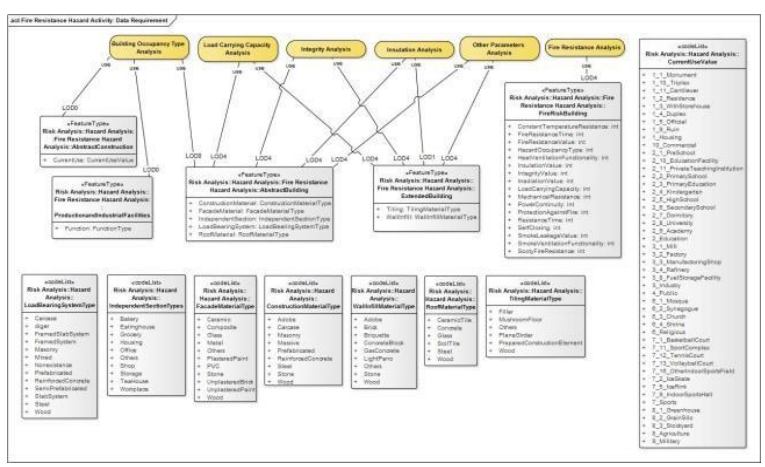

Figure 8: Geo-information requirements diagram of "fire resistance hazard analysis" activity

\subsection{Geo-information Requirements Analysis for Industrial Fire Disaster}

3D geo-information requirements of the process are determined with combining the activity requirements. Different LOD requirements might be determined for the same object in different activities of the process. The highest level of detail required for the object is used as LOD requirement in geo-information requirements analysis of the process. Figure 9 shows the geoinformation requirements diagram of "hazard analysis" process which has "fire resistance hazard analysis" activity explained in 
Figure 8. The yellow classes are created for presenting the LODO geo-information requirements. The green classes are used to show the LOD1 geo-information requirements. The classes in purple are defined for showing LOD2, LOD3 and LOD4 geoinformation requirements.

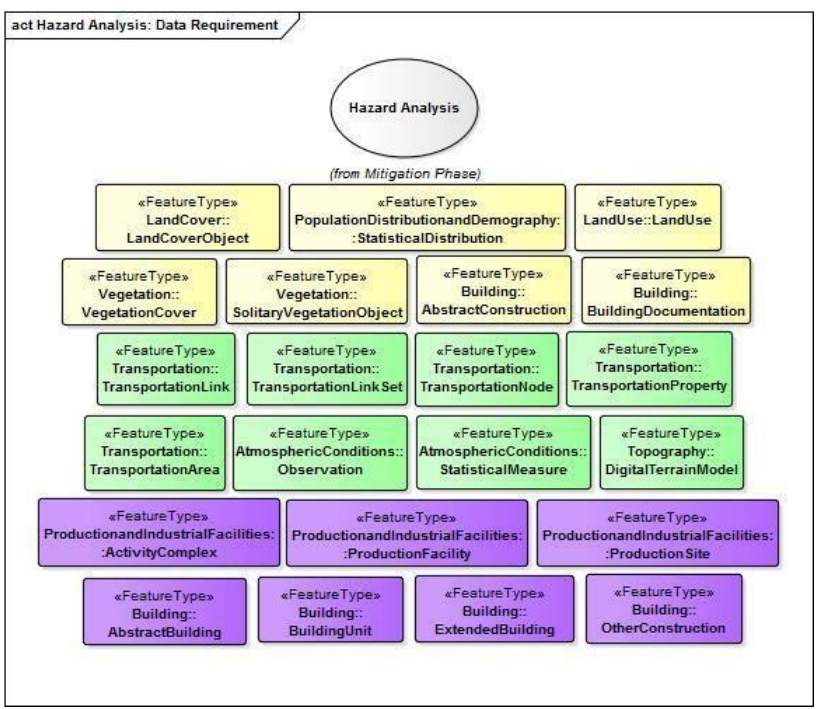

Figure 9: Geo-information requirement diagram of "hazard analysis" process

3D geo-information requirements for processes compose the requirements of the management phases of industrial fire disaster. Table 2 involves the 3D geo-information requirements of the phases of mitigation, preparation, response and recovery for industrial fire disaster management.

\begin{tabular}{|c|c|c|c|c|c|c|c|c|c|c|c|c|}
\hline \multirow{2}{*}{ FEATURE TYPES } & \multicolumn{3}{|c|}{ MITIGATION PHASE } & \multicolumn{3}{|c|}{\begin{tabular}{|l} 
PREPARATION PHASE \\
\end{tabular}} & \multicolumn{3}{|c|}{ RESPONSE PHASE } & \multicolumn{3}{|c|}{ RECOVERY PHASE } \\
\hline & LODO & LODI & LOD2-4 & LODO & LOD1 & LOD2-4 & LODO & LODI & LOD2-4 & LODO & LOD1 & LOD2-4 \\
\hline Addresses & & & & & & & + & & & & & \\
\hline Building & & & + & & & + & & & + & & & + \\
\hline Cadastral Parcels & & & & & & & & & & + & & \\
\hline CityFurniture & + & & & + & & & + & & & + & & \\
\hline Hydrography & + & & & + & & & & & & + & & \\
\hline Land Cover & + & & & + & & & & & & + & & \\
\hline Land Use & + & & & + & & & + & & & + & & \\
\hline $\begin{array}{l}\text { Utility and } \\
\text { Govermmental Services }\end{array}$ & & + & & & + & & & + & & & + & \\
\hline Trangportation & & + & & & + & & & & + & & + & \\
\hline Topography & & + & & & + & & & + & & & + & \\
\hline Vegetation & + & & & + & & & & & & + & & \\
\hline Bridge & & + & & & + & & & & + & & + & \\
\hline Tumnel & & + & & & + & & & & + & & + & \\
\hline Protected Sites & & & + & & & + & & & + & & & + \\
\hline $\begin{array}{l}\text { Area Management / } \\
\text { Regulation Zones/ }\end{array}$ & + & & & + & & & + & & & + & & \\
\hline Atmospheric Conditions & & + & & & + & & & & + & & + & \\
\hline Energy Resources & & & + & & & + & & & + & & & + \\
\hline Natural Risk Zones & + & & & + & & & + & & & + & & \\
\hline $\begin{array}{l}\text { Population Distribution } \\
\text { and Demography }\end{array}$ & & & + & & & + & & & + & & & + \\
\hline $\begin{array}{l}\text { Production and } \\
\text { Industrial Facilities }\end{array}$ & & & + & & & + & & & + & & & + \\
\hline
\end{tabular}

Table 2. Geo-information requirement analysis for the management phases of industrial fire disaster

From the use cases, a list of requirements for 3D geoinformation has been identified. Diagrams of 3D geo-information requirements for processes compose the industrial fire disaster geo-information requirements diagram. Figure 10, which involves the general feature types needed to manage the industrial fire disaster and needed scales of objects with LOD concept, is a UML class diagram presenting 3D geo-information requirements for industrial fire disaster.

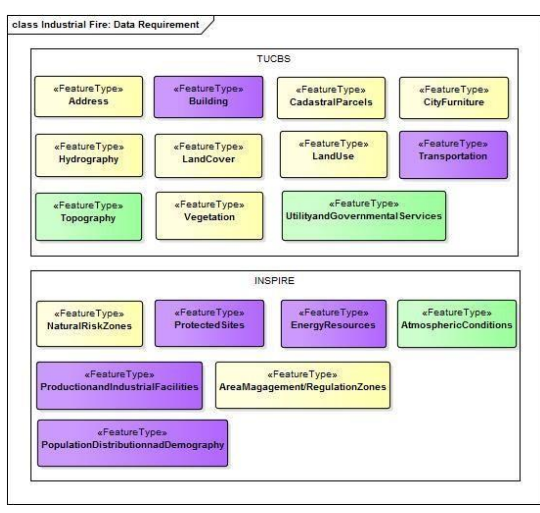

Figure 10: 3D geo-information requirements diagram for industrial fire disaster

Building feature type is the best important data set for managing the industrial fire disaster. Required is information on the buildings, in particular the current use value. Furthermore, the material of the construction and of the facade, the number of floors, the description of floors, load bearing system, openings, the height above ground and etc. are needed. For industrial fire disaster management, buildings with flat roofs, addresses, the 3D representation of openings, internal and external installations, rooms and building units are needed in addition. TUCBS building data set is not adequate to manage the industrial fire disaster. Therefore, production and industrial facilities feature type, which has information about activity and dangerous substances, is added to diagram for defining $3 \mathrm{D}$ geoinformation requirements of industrial fire disaster. The external reference to the building in other data sets is useful to obtain further information on the building.

Besides building data set, different types of objects in the 3D geoinformation requirements diagram for industrial disaster management are transportation, topography, and utility and governmental services from TUCBS and protected sites, energy resources, atmospheric conditions, production and industrial facilities, and population distribution and demography from Inspire.

Building, transportation, protected sites, energy resources, production and industrial facilities, and population distribution and demography feature types are required with their LOD2-4 information. That is to say, these data sets are essential for 3D geo-information to manage industrial fire disaster.

\section{CONCLUSIONS AND FURTHER RESEARCH}

This paper presented an approach for formalising the DEM processes in Turkey. The conceptualisation of approach consists of process, activity, task, sector, actor and data. 42 processes are determined based on the legislation for DEM in Turkey to integrate the 12 disaster types defined for Turkey. 234 activities and the tasks of these activities are determined within 42 processes for industrial fire disaster. 28 sectors and actors involved in DEM are determined from legislations.

In this study, the approach have been presented for an integrated DEMS with mitigation, preparation, response and recovery phases. Thus, 3D geo-information requirement analysis as an important aspect of DEMS have been focused. We argue that 3D geo-information that provide advanced visualisation, analysis and interaction to the actors involved in DEM have the potential to improve the DEM processes. 3D geo-information can resolve many perception problems and improve the activity management. 
This paper reported the investigation of 3D geo-information requirements for DEM in Turkey with the literature study and legislations analysis.

The different types of data sets in the 3D geo-information requirements analysis are defined: addresses, building, transportation, topography, utility and governmental services, protected sites, energy resources, atmospheric conditions, production and industrial facilities, and population distribution and demography. These objects could be visualized and analysed in both $2 \mathrm{D}$ and $3 \mathrm{D}$. Some data sets have a negative importance ratio, in other words, some data sets are not needed in 3D DEMS model.

In the further research, this $3 \mathrm{D}$ geo-information requirements analysis will be performed for earthquake, flood and forest fire disasters. LOD defined by CityGML may not be sufficient for all these disaster types. Combinations of LODs may be more appropriate. Future research will investigate these possibilities in detail.

According to use case descriptions and 3D geo-information requirements analysis, data related to DEM will be modelled as a further research. Beside the standard data of a 3D model, additional DEM related data, which are relevant to a specific type of disaster, are also of need. These data will be added to model in the further research.

Furthermore, dynamic data which is critical for the response phase of DEM will be added to model. This research ignores several important elements to ensure a real-time DEM response system. The further research will focus on 3D spatiotemporal model to maintain operational and situational information in response phase of DEM.

Furthermore, data related to DEM will be added to CityGML as Application Domain Extensions (ADE). This ADEs will be related to integrated process of DEM. First ADE research will performed for integrated hazard process.

\section{REFERENCES}

Aydinoglu, A. C., Demir, E. and Yomralioglu, T. (2011). An approach to Use geo-information effectively in disaster and emergency management activities in Turkey. Proceedings of the FIG Congress 2011, Marrakesh, Morocco.

Benson, C. and Twigg, J. (2007). Tools for mainstreaming disaster risk reduction, Prevention Consortium.

Bhugra, D. (2005). Cultural factors and disasters. WHO Conference on the Health Aspects of the Tsunami Disaster, 4-6 May, Phuket, Thailand.

Demir Ozbek, E., Ates, S. and Yomralioglu, T. (2015). Using geo-data corporately on the response phase of emergency management. ISPR Geospatial Week, 28 September- 2 October, La Grande Motte, France.

Dilo, A. and Zlatanova, S. (2008). Spatiotemporal modelling for disaster management in the Netherlands. Gi4DM Conference, 46 August, 2008, Harbin, China.

FEMA, (2006). Preparedness for emergency response. Fundamentals of Emergency Management, Chapter 9: Retrieved from http://training.fema.gov/hiedu/aemrc/booksdownload/fem/
Franke, J. and Charoy, F. (2010). Design of a collaborative disaster response process management system. In Lewkowicz, M., Hassanaly, P., Rohde, M. and Wulf, V. (Eds.). 9th International Conference on the Design of Cooperative Systems, London, pp. 57-77.

Kemec, S., Zlatanova, S. and Duzgun, S. (2012). A new LoD definition hierarchy for 3D city models used for natural disaster risk communication tool. In: Bandrova, T., Konecny, M. and Zhelezov, G. (Eds.). Proceedings of the 4th International Conference on Cartography \& GIS, Volume 2, Albena, Bulgaria, pp. 95-104.

Kemec, S. (2011). A conceptual framework for 3D urban disaster risk visualization in geo-spatial environment. $\mathrm{PhD}$ thesis, Geodetic and Geographic Information Technologies Department, Middle East Technical University.

Kemec, S., Duzgun S. and Zlatanova, S. (2009). A conceptual framework for $3 \mathrm{D}$ visualization to support urban disaster management. In: Konecny, M. and Zlatanova, S. (Eds.). Proceedings of the Joint Symposium of ICA WG on CEWaCM and JBGIS GI4DM, Prague, Czech Republic, pp. 268-278.

Kolbe, T. H., Groger, G. and Plumer L., (2005). CityGMLinteroperable access to 3D city models. In: Oosterom, Zlatanova, Fendel (Eds.). Proceedings of the Int. Symposium on Geo-information for Disaster Management, Delft, Netherlands.

Kolbe, T. (2009). Representing and exchanging 3D city models with CityGML. In: Lee, J. and Zlatanova, S. 3D Geoinformation Sciences, Springer, pp. 15-33

OGC. (2007). Candidate OpenGIS CityGML Implementation Specification.

Pundt, H., (2008). The semantic mismatch as limiting factor for the use of geospatial information. In: Geospatial Information Technology for Emergency Response, Taylor \& Francis Group, London, pp. 243-255.

Sackmann, S., and Hofmann, M. and Betke, H. (2013). Towards a model-based analysis of place-related information in disaster response workflows. In: Comes, T., Fiedrich, F., Fortier, S., Geldermann, J. and Müller, T (Eds.). Proceedings of the 10th International ISCRAM Conference. - Baden-Baden, Germany.

Turkish Disaster Response Plan. (2013). T.C. Official Gazette, 20 December 2013

Vakis, R. (2006). Complementing natural disasters management. The Role of Social Protection. Social Protection SP Discussion Paper No 0543,

Xu, W. and Zlatanova, S. (2007). Ontologies for disaster management. In: Geomatics Solutions for Disaster Management. Springer-Verlag Berlin, Heidelberg, pp. 185-200.

Zlatanova, S. and Holweg, D. (2004). 3D Geo-information in Emergency Response: a Framework. Proceedings of the Fourth International Symposium on Mobile Mapping Technology (MMT'2004), Kunming, China.

Zlatanova, S., Oosterom, P. V. and Verbree, E. (2004). 3D Technology for Improving Disaster Management: Geo-DBMS and Positioning. Proceedings of the XXth ISPRS Congress, Istanbul, Turkey. 
Zlatanova, S. (2008). SII for emergency response: the 3D challenges. In: Chen, J., Jiang, J. and Nayak, S. (Eds,). Proceedings of the XXI ISPRS Congress, Part B4-TYC IV, July 2008, Beijing, pp. 1631-1637.

Zlatanova, S., (2010). Formal modelling of tasks to support search of geo-information in emergency response, In: Das (Eds.). International symposium climate change \& disaster management, Noida, India, GIS Development Pvt. Ltd., pp. 26-36.

Zlatanova, S., Stoter, J. and Isikdag, U. (2012). Standards for exchange and storage of 3D information: challenges and opportunities for emergency response. In: Bandrova, T., Konecny, M. and Zhelezov, G. (Eds.). Proceedings of the 4th International Conference on Cartography \& GIS, Volume 2, Albena, Bulgaria, pp. 17-28.

\section{ACKNOWLEDGEMENTS}

This work was supported by the Scientific and Technological Research Council of Turkey (TUBITAK) under 2214

International Doctoral Research Fellowship Program. 